\title{
Research and Analysis of the Image of Peach in Ancient Chinese Literature
}

\author{
Junqiang Gao \\ Weinan Normal University, Weinan, 714000, China
}

\begin{abstract}
Keywords: Ancient Chinese Literature; Peach Imagery; Theme; Culture
\end{abstract}
\begin{abstract}
Imagery is an objective phenomenon, which integrates the author's subjective feelings, but also the life and soul of poetry. There are many works in Chinese classical literature that express the aesthetic image through the description of flowers. For example, the Chinese advocate Peony and the Song Dynasty praise the plum blossoms. It can be said that flower imagery is an important aesthetic image in Chinese ancient literature. This aesthetic image is not purely but also the cultural elements of the times such as psychology, art, literature and religion of the ancient people. Therefore, the study of the flower literature and related culture can form one for the literati's creative emotion, creative psychology, the background of the times, and the aesthetic psychology Comprehensive and profound understanding. Peach blossoming image, the ancient text more joyful shape, subject to its color, but also indulge in the fragility of the passing flowers, so many literary works contain peach blossom image rich. The article mainly studies the image of peach blossom in ancient Chinese literature.
\end{abstract}

\section{Research on the Peach Theme in Different Periods}

Since the Qin Dynasty to the late Qing Dynasty, different historical periods in the literary works of peach theme are very rich, the following analysis of the specific application of peach themes according to different dynasties:

It can be said that the description of peach in literary works in the pre-Qin period provided rich inspiration for future literary creation and was also the foundation of later peach blossom. As the working people in the pre-Qin period mainly focused on simple agricultural activities, the literary connotations of peach blossom were also simpler and simpler. For example, "the peach died, burning its heart," and in just eight words, the peach blossoms beautifully, while the peaches are plump and juicy. The peach symbolizes youthful health. Therefore, it is used to describe the outline of a young woman's beauty and vitality. Peach in the pre-Qin period is mainly used to praise the beauty of women.

The Wei, Jin and the Southern and Northern Dynasties are an important period in the history of peach blossom and peach blossom in the history of peach blossom. It is the "conscious" era of the beauty of peach blossom literature. The description of peach blossom in this period mostly contrasts the beauty of peach blossom by describing the surroundings and surroundings of peach blossom. This is because the Southern Dynasties aesthetic understanding of things is still in its infancy, so its performance is a little immature. However, there are still some successful works, such as Shen Yue's "Ancestral Peach", "Hongying has been illuminated, the complex contains the sunlight," and "resentment and deepness," the style of writing expresses the sensitive and delicate feelings of the poet.

It can be said that the peach blossom theme ushered in one of the most prosperous periods in the literature of the Tang Dynasty. The Tang Dynasty was an era of all-round economic, cultural and religious development. Its thriving and prosperous historical background made the culture of Tang Dynasty the beauty of women displayed has a profound understanding, a feature that is reflected in the prosperity of Tang poetry culture. In the Tang Dynasty, the highly developed garden art expanded the distribution of peach blossom. Therefore, the literati of Tang Dynasty expressed the vivid image of peach beauty features with keen observation and mature artistic skills. For example, through the theme peach peach aesthetic performance of the poem, "Peach is not yet open, calyx full of fragrant branches," such as "red peach tender, green willow new" and so on, from different 
perspectives, Showing the aesthetic connotation of peach; In addition, the literati of Tang Dynasty also highlighted the beauty of peach through the collocation of colors and the background, for example, "Peach blossom, peach leaf one branch open" is set off by peach leaf; and " Red Pepper Peach Tower "to Liu Si set off, etc., the vitality of the special spring beauty set off.

Compared with the Tang Dynasty, the Song Dynasty was an era of extravagant and turbulent coexistence. In the early Song Dynasty, the social and economic development was stable and people lived a comfortable and comfortable life. As a result, life was reported with great enthusiasm and higher and higher demands on the quality of life. To the end of the Song Dynasty, the current situation was volatile. Many literati had no enthusiasm to serve the country. Therefore, many peach blossom appeared in literary works in this period. Such as Fan Zhongyan "suddenly into Taoyuan Road, Mau strange mountain Weng Yu," is the expression of Fan Gong's fame and fortune indifferent, eager to spend alone Taoyuan "Yi Yu." It can be said that the image of the Song Dynasty peach blossom is the inheritance of Tao Yuanming's "Peach Blossom Spring" in order to develop, especially the writer Zhang Yan as the representative, in "Gao Ai Shan seclusion" wrote "Unexpectedly in the mountains Qin Jin, Taoyuan this degree is difficult to recognize", " Longevity, laughter yuan non-shortcut, "these lonely, ethereal suggestion to make it more in line with Tao Yuanming.

To a certain extent, the pursuit of eroticism in the description of the peach blossom of the Yuan Dynasty is even more obvious. From a large number of elements, we can get a glimpse of the eroticism. Such as Wu Changling's "Zhang Tian Shi Hua Yi Xue Yue," bold and frank language will love the flesh and blood of men and women love the place where compared to Taoyuan hole. This is because the Yuan Dynasty was dominated by aliens and the Han nationality literati were unbalanced in their life. In addition to the distress of life, they were often lingering in the vicinities, palaces, prostitutes, dancers' palaces and brothels, thus making the Yuan Dynasty comedy show the strong erotic component. If we say that the images of peach blossom in Yuan and Ming dynasties focus on erotic imagination and pursuit, the image of peach blossom in Qing dynasty is a profound interpretation and interpretation of Tao Yuanming's poetic mood. For example, "Dream of the Mid-Autumn Festival," wrote "But see both sides of the embankment, both willow apricot, red and green meet, such as Wuling Taoyuan general"; another example, "Sui and Tang Romance" also described "many peach trees inside, Wuling Taoyuan scene "and so on, these are the landscape characteristics of Taoyuan identity and acceptance.

\section{The Image Analysis of Peach in Ancient Literature}

Analysis of different periods of literary works of peach theme, the classical Chinese literature can be described in the image of the peach for the following categories:

Peach blossoming in the flourishing spring business, not only beautiful and delicate colors and feminine, and women also have this feature, according to the characteristics of the original image of peach, classical poetry and more Yu Taohua Yu beauty. For example, the Tang Dynasty Poet Li Bai's "long line", with delicate peach blossoming backdrop of girls, write "self-pity fifteen, color peach red"; another example Cuihuo "peach blossom red" This kind of symbol and metaphor means reflects the ancient literati's poetic creation of Qingling, refined and elegant. Of course, there are differences in humane ideals conveyed by Tao Yu Yu-mei in different ages and different social environments. The differences can be divided into the following categories: one is dignified and feminine in IKEA IKEA such as ", With the blessings of peach blossoms of the people of the owner's home thriving. The second is the sweet and lovely peach woman $\mathrm{Li}$, such as "peach fan" in the description of Li Xiangjun is "Xinxi is Magnolia tree, less than Dongfeng peach plum." Another is the little girl jasper, such as "peach blossom red" and so on. Thus, the connotation of women's culture has already become the people's aesthetic basis for peach blossom, forming an inherent cognitive, peach blossom and women associate with each other has also formed an inherent awareness, therefore, peach became the typical female image in literary works Representatives have long been widely accepted and endorsed.

Peach has always been a fantasy extragalactic material in literary works, which is inextricably 
linked with Taoism. Peach itself is a free, seclusion of flowers, the most classic "Peach Blossom Spring" on the use of peach Lin opened up a self-satisfied ideal space; another example, "You Ming Lu" Liu Chen, Ruan Zhao into the Tiantai peach Fairy tale and so on. Since ancient times, the literati have never met their dreams and can not exert their ambitions in the turbulent current situation. Therefore, they are eager to love the landscape and live seclusion in the world. In the literary works, the ideal of using peach to express hermitism is mostly because of the literati's pursuit of ideal life, but she is forced to create an untouched and strifeless paradise in her works. Another example is "Tongji Zhongfu dream of Taoyuan," wrote "water depth, no one knows ancient and modern", through the prosperous peach, deep Bitan create a distant, quiet mood, which reflects the poet's strong Hermit thoughts. It is through these images of peach, the ancient scholar to demonstrate to the world their high esteem and Emotion.

Peach flowering period is short, easy to fall, and the feeling of flowers, Spring Spring is an eternal complex, and peach blossom caused by melancholy is very easy to lead people to love, especially sad love. For example, Liu Yuxi's "tour branch words," "red flowers easy to decline like Lang meaning unlimited flow like Lennon," the decline of love through the decline of peach disappointment. Another example is the love of $\mathrm{Lu}$ You and cousin through the "Chai Toufeng" expression most vividly, "Peach Blossoms, Leisure Pool House, Mountain League Although in the Kam book is difficult to care," wrote a mournful sad, touching Fei side; "Daiyu's" funeral flower word "is also seen in peach blight and self-pity of sadness, through the loss of peach blossom jade to express their own frustrated love, write" once the spring to do the old, Death two unknown "verse. In short, the image of peach "falling red" renders endless sadness, and peach blossom is associated with love, reminding people of the hidden sourness behind the beautiful face and expressing the mood that the peach blossoms like a woman in full bloom because of the sadness and witheredness.

From a biological point of view, peach opening in Jingzhe, when everything revives, making Peach with the original Eros gene. Peach blossom is the season of surging life. The opening of peach blossom is closely related to the outbreak of the eroticism between men and women. Therefore, Peach blossom expresses the color of the combination of the two sexes. Peach blossoms also become the carriers of erotic images such as beauty and beauty. Such as Liang Wudi Xiao Gang's "cockroach high tree top" in the "Peach Full Coverage, Golden Gate half hidden Church, when Xin Yan, Fu Bishan ducks" description, the peach's erotic means appeared. In the Southern Dynasties, the father of Ashes, "Asteroid Horse" is written "as Yao Blossom Path", where the "Peach Blossom Path" is the path leading to the prostitutes. Another example is the spread of the Tang Dynasty, "I song" "Dong Fu deep spring into the long, Yamamoto no fragrance from the main ...... For a kind of Peach Nguyen Lang", which Dong Fu, Nguyen Lang men and women have a good hint expressed the hidden Containing the erotic implications. The erotic image through the peach expression more direct explicit "Rosary Palace", but also have "fairy fairy makeup, Peach Blossom hole every Lang, Wushan goddess pick the cloud, Chu Tairen empty emptied" verse, regardless of Is peach hole or Wushan goddess, are the expression of the erotic means.

\section{Conclusion}

In short, the peach color is pretty and colorful. It has a great touch on the emotions and emotions of the Chinese literati. Therefore, the psychological elements of the aesthetic body are infiltrated into the peach blossom. Chinese classical literature gives Peach Blossom "the image of beauty, the symbol of sadness, the metaphor of sexuality, the feeling of seclusion" not only because of some qualities and personalities Peach has made it possible for scholar-scholars to send love to the peach, but also because of the transmission of literary works, in the ancient literati formed a specific image. As an image carrier jointly recognized by the Chinese people, Peach Blossom is bound to become Chinese plum and chrysanthemum, becoming the accumulation of the memory and psychology of our national collective and forming the peach blossom culture with unique characteristics in China. 


\section{References}

[1] Yuan Chuanzhang. "Peach Blossom Spring Festival poem" doubts about [J]. Anqing Teachers College, 2014 (1): 309-310

[2] Wang Ying, Eagle and Crane. The Evolution of Flower Images in Poems of Tang and Song Dynasty [J]. Review, 2015 (5): 152.

[3] Zhang Lingfeng. Analysis of Peach Blossom Image in Chinese Classical Literature [J]. Northern Literature, 2014, (3): 32-33

[4] Pan Ting. Research on the Theme and Image of Peach in Ancient Chinese Literature [J] .Jiannan Literature, 2013, (12): 50-51

[5] by Na. Talk about the image of peach in ancient Chinese literature [J]. Jixi University: Integrated, 2012,12 (7): 114-115

[6] Dang Hongyan. Peach blossom Chinese ancient literature themes and images [M]. Beijing: China Social Sciences Publishing House, 2009: 589-590

[7] Lin Xuehua. Analysis of "Peach Blossoms" in Chinese Classical Poems [J]. Journal and Appreciation (Teaching and Research Version), 2017 (5): 156-157 